\title{
L-4-Boronophenylalanine (all around the one molecule)
}

\author{
Igor B. Sivaev* and Vladimir I. Bregadze \\ Laboratory of Organoaluminum and Organoboron Compounds, \\ A.N.Nesmeyanov Institute of Organoelement Compounds, Russian Academy of Sciences \\ 28 Vavilov str., 119991 Moscow, Russia \\ E-mail: sivaev@ineos.ac.ru
}

\section{Dedicated to Prof. Irina Beletskaya on the occasion of her 75 anniversary}

\begin{abstract}
L-4-Boronophenylalanine (L-BPA) is one of the two clinically approved drugs for boron neutron capture therapy of cancer. This mini-review describes various aspects of its chemistry: methods of synthesis, drug formulation, modifications directed to study its biodistribution and pharmacokinetics, as well as the application of L-BPA in organic synthesis.
\end{abstract}

Keywords: 4-Boronophenylalanine (BPA), synthesis, drug formulation, biodistribution and pharmacokinetics, Suzuki-Miyaura reaction, Boron Neutron Capture Therapy (BNCT)

\section{Contents}

1. Introduction

2. Synthesis of 4-Boronophenylalanine (BPA)

2.1. An introduction of amino acid group

2.2. Coupling alanine with phenyl boronic acid

2.3. Introduction of boronic acid group into phenylalanine

3. Drug Formulation and Delivery

4. Study of Biodistribution and Pharmacokinetics

5. Non-medical Applications - BPA in Organic Synthesis

6. Conclusions

7. References

\section{Introduction}

4-Boronophenylalanine (BPA, Scheme 1) is a boronated amino acid, which exhibits a specific affinity for tumors. Its ${ }^{10} \mathrm{~B}$-enriched form has been clinically approved for Boron Neutron 
Capture Therapy (BNCT) of cancer, a binary method for the treatment of cancer, which is based on the nuclear reaction of two essentially nontoxic species, nonradioactive ${ }^{10} \mathrm{~B}$ and low-energy thermal neutrons. The neutron-capture reaction by ${ }^{10} \mathrm{~B}$ produces an $\alpha$-particle ${ }^{4} \mathrm{He}^{2+}$ and ${ }^{7} \mathrm{Li}^{3+}$ ion together with $2.4 \mathrm{MeV}$ of kinetic energy and a $480 \mathrm{keV}$ photon. These high-linear-energy transfer ions dissipate their kinetic energy before traveling one cell diameter $(5-9 \mu \mathrm{m})$ in biological tissues, ensuring their potential for precise cell killing. Therefore, high accumulation and selective delivery of boron into the tumor tissue are the most important requirements to achieve efficient neutron capture therapy of cancer. ${ }^{1,2}$

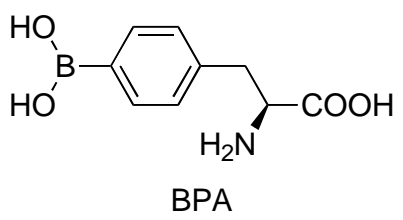

In this review, various aspects of the chemistry of 4-boronophenylalanine will be considered, including methods of its synthesis, drug formulation, modifications directed to study its biodistribution and pharmacokinetics, as well as the application of L-BPA in organic synthesis.

\section{Synthesis of 4-Boronophenylalanine}

The growing significance of BPA as a BNCT agent as well as its synthetic utility in the preparation of 4-substituted phenylalanine derivatives resulted in a development of numerous methods of its synthesis based on different synthetic methods. At present, preparation of this rather simple compound can be considered as a striking illustration of the wealth and diversity of the arsenal of organic syntheses.

All described methods of synthesis of BPA could be divided into three groups depending on the bond formed in the key step of BPA synthesis.

\subsection{Introduction of the amino acid group}

The first group includes methods based on the formation of the $\mathrm{C} 1-\mathrm{C} 2$ bond between various synthetic equivalents of the amino acid and the boron-containing benzyl or benzaldehyde fragment.

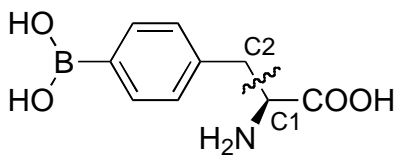

This approach was used in the first synthesis of BPA by Snyder et al. ${ }^{3}$ featuring the reaction of 4-dihydroxyborylbenzyl bromide with diethyl acetamidomalonate followed by alkaline hydrolysis and decarboxylation (Scheme 1). 


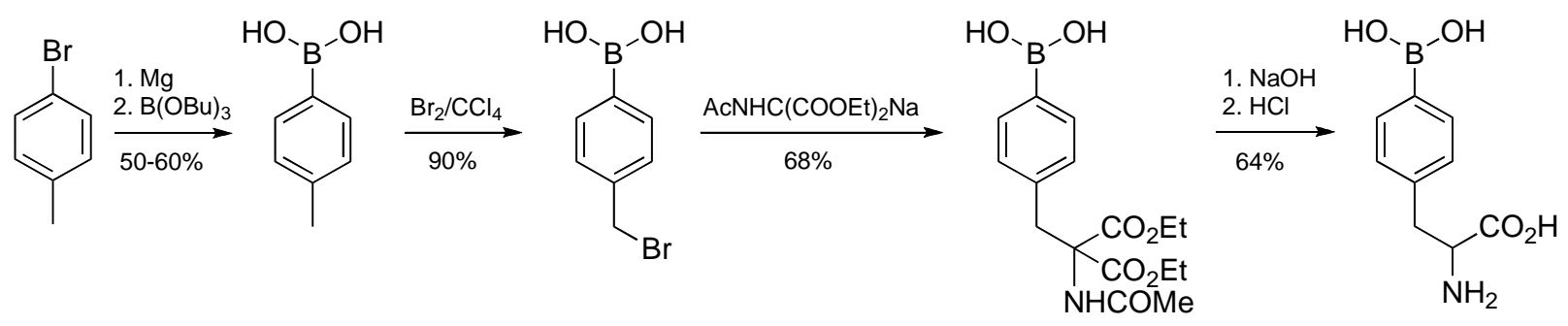

\section{Scheme 1}

Unfortunately, in this method the BPA yield did not exceed $40 \%$ (based on $p$-tolylboronic acid). Better yields have been obtained after protection of the dihydroxyboryl group with diols resulting in cyclic ethers of boronic acid. For instance, the reaction of 4-dihydroxyborylbenzyl bromide with 2,3-dimethyl-2,3-butanediol gives 4-(pinacolylborono)benzyl bromide, ${ }^{4}$ which in turn, reacts with ethyl 2-(diphenylmethyleneamino)acetate to give protected $\mathrm{BPA}^{5}$ (Scheme 2).

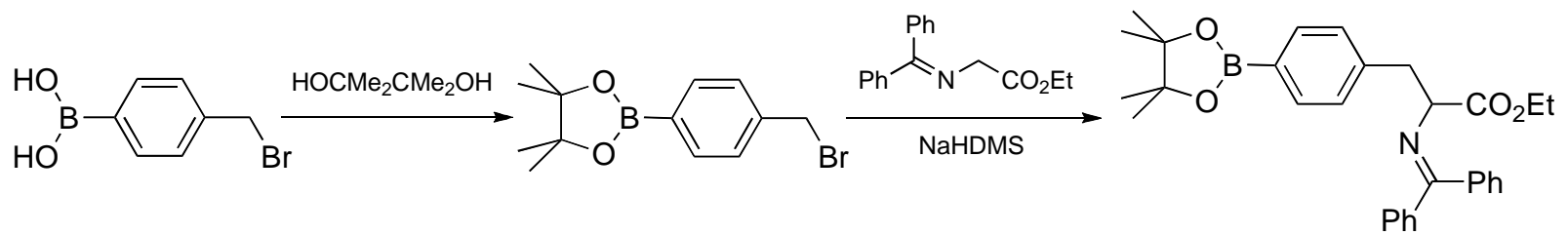

\section{Scheme 2}

The racemic mixture of L- and D-BPA can be separated by transformation of the amino acids into ethyl esters followed by selective hydrolysis of the L-isomer using the proteolytic enzyme chemotrypsin. ${ }^{6}$

The same approach can be used for the enantioselective synthesis of L-BPA. One synthesis is based on an enantioselective alkylation of (2R)-(-)-2,5-dihydro-2-isopropyl-3,6-dimethoxypyrazine and gives L-BPA in $22 \%$ yield $^{7}$ (Scheme 3 ).
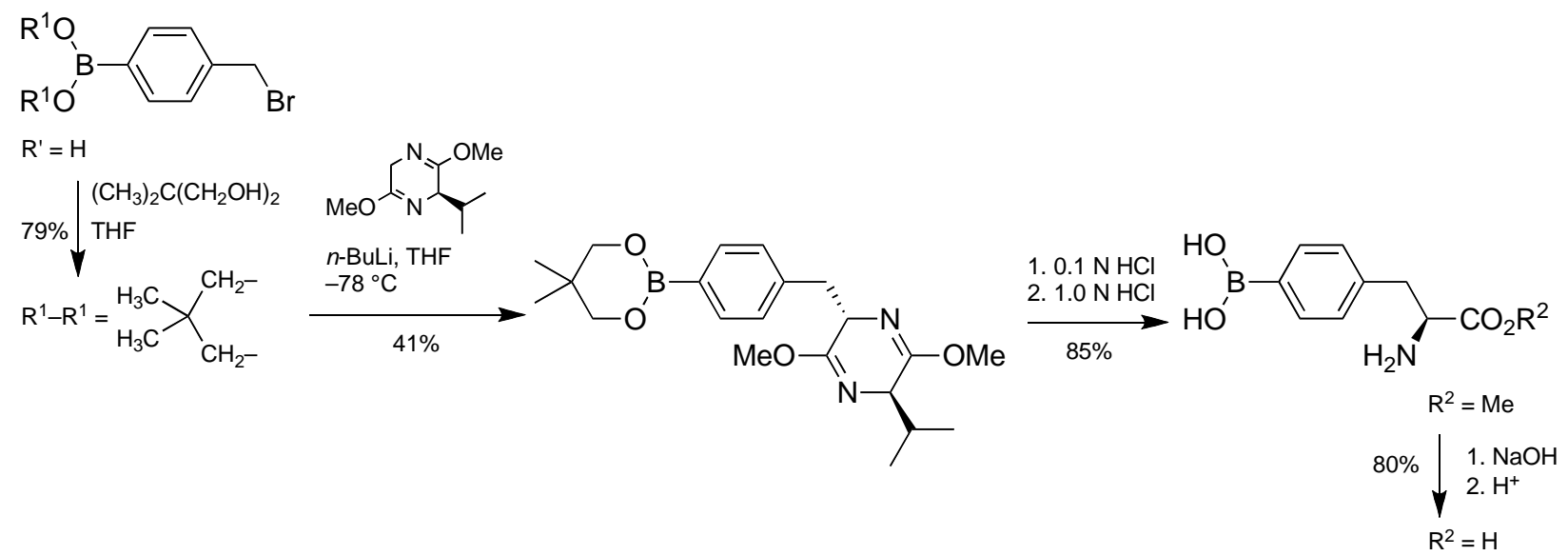

\section{Scheme 3}


It should be noted that alkaline hydrolysis of the methyl ether at the last step results in some racemization of the amino acid. The racemization has been avoided by the enzymatic hydrolysis with chymotrypsin, however, the yield of this step drops to $64 \%{ }^{7}$

Another enantioselective synthesis of L-BPA utilizes Seebach's imidazolidinone (Scheme 4). ${ }^{5}$

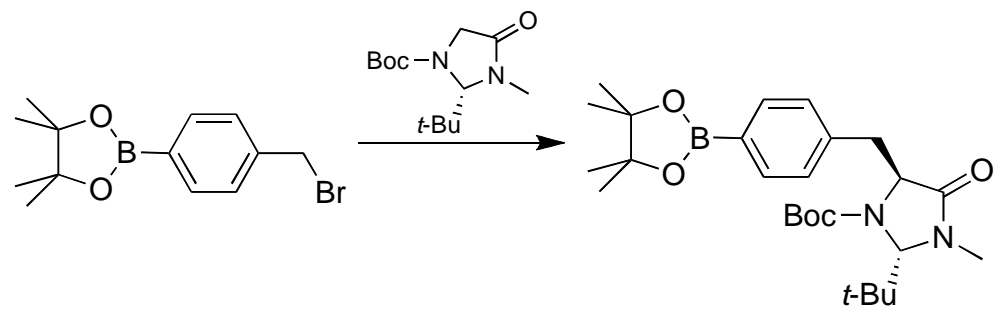

\section{Scheme 4}

Another effective approach makes use of $p$-formylboronic acid as the starting material. Protection of the dihydroxyboryl group with $N$-methyldiethanolamine ${ }^{8}$ followed by the reaction of the formyl group with sodium salt of ethyl isocyanoacetate, catalytical hydrogenation of the double bond formed, and deprotection affords BPA in 52\% yield (Scheme 5). ${ }^{9}$
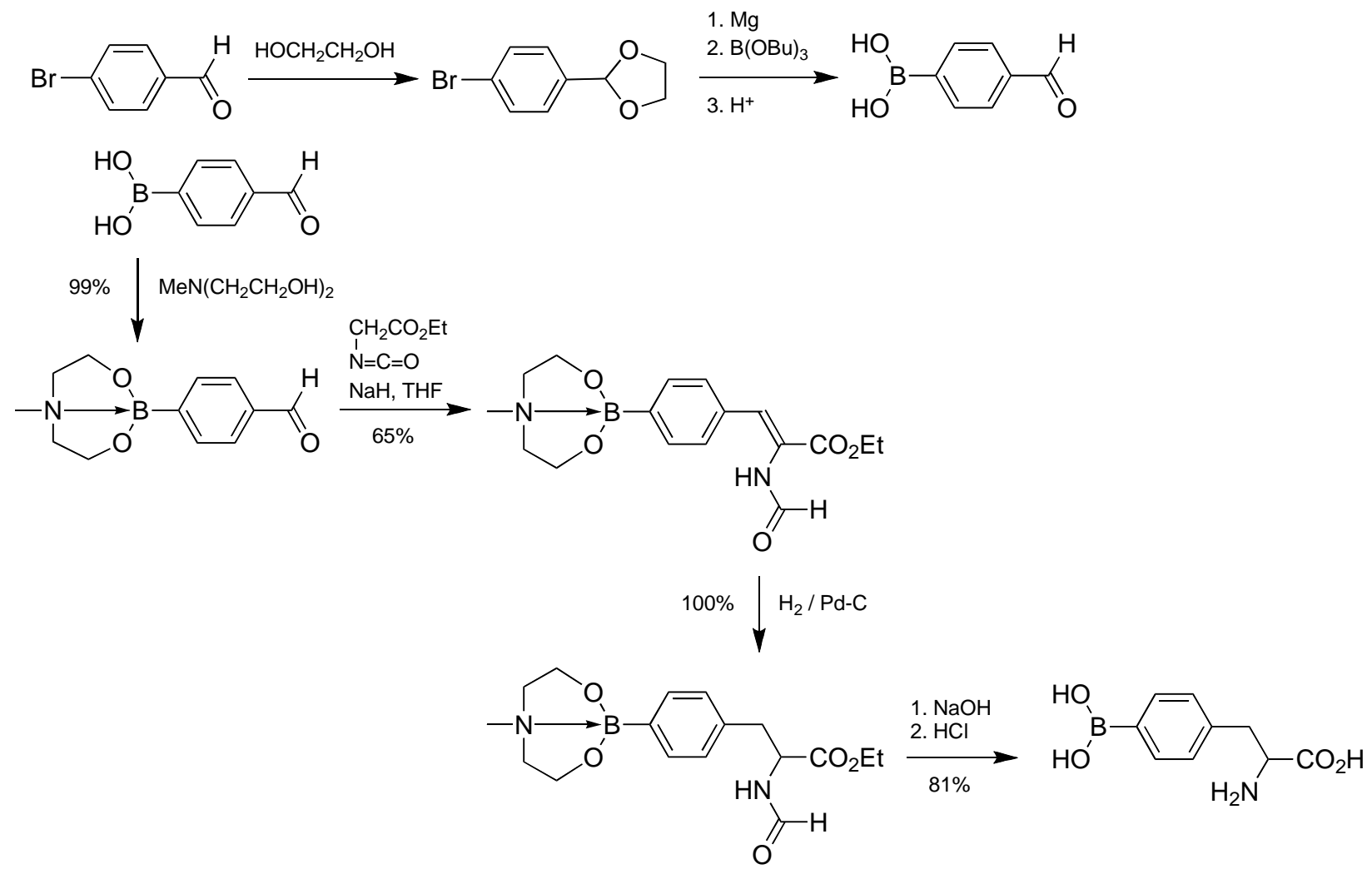

\section{Scheme 5}


The other method based on $p$-formylboronic acid includes protection of the dihydroxyboryl function with 2,2-dimethylpropan-1,3-diol followed by the reaction with $N$-(benzyloxycarbonyl) phosphonoglycine trimethyl ester. The subsequent catalytic hydrogenation of the double bond and deprotection results in formation of BPA in $62 \%$ yield (Scheme 6$){ }^{10}$

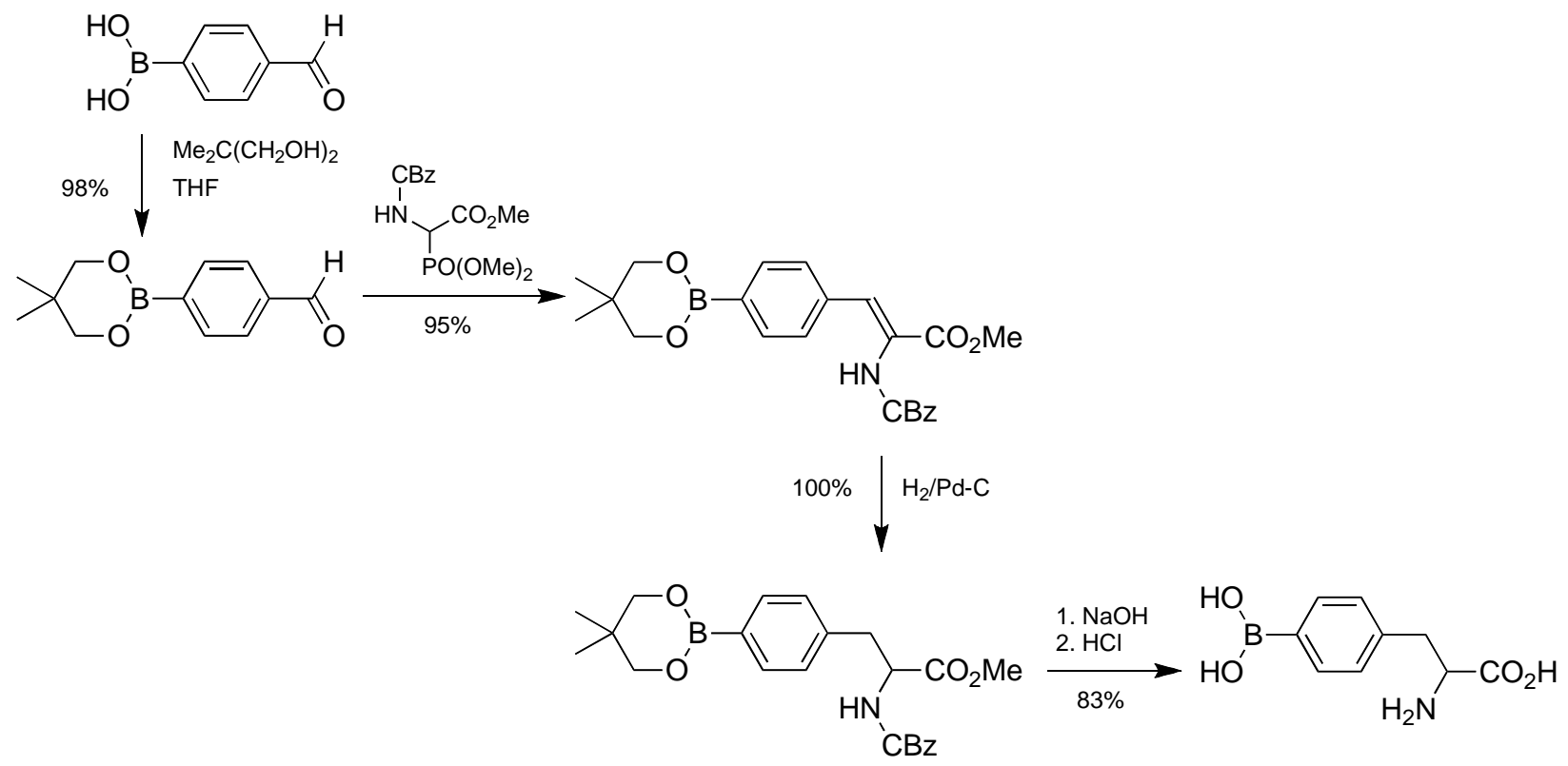

\section{Scheme 6}

The enantioselective synthesis of L-BPA based on catalytic hydrogenation with the chiral catalyst (1,5-cyclooctadiene)[R-1,2-bis(diphenylphosphino)propane]rhodium(I) tetrafluoroborate has been proposed (Scheme 7). ${ }^{11}$

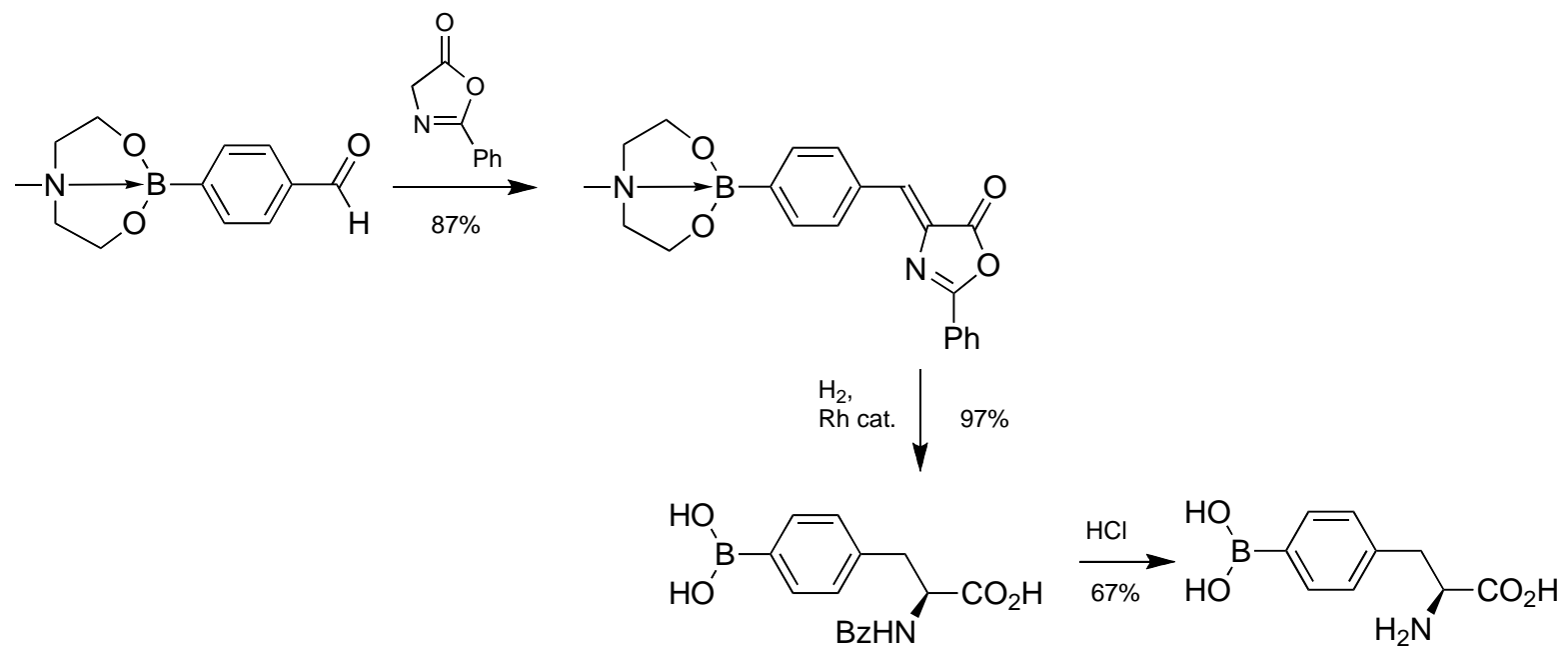

\section{Scheme 7}




\subsection{Coupling of alanine with phenyl boronic acid}

The second group of synthetic methods of BPA is based on the formation of the $\mathrm{C}_{2}-\mathrm{C}_{\mathrm{ar}}$ bond between the phenyl ring and the L-alanine fragment resulting in enantiomerically pure L-BPA.

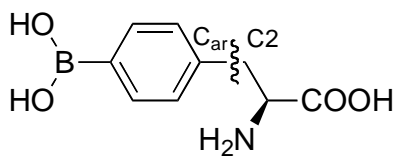

At present, only one example of this approach has been reported (Scheme 8). ${ }^{12}$ Unfortunately, this synthesis requires the preliminary preparation of an L-alanine zinc derivative and gives a rather low yield of the target product ( $40 \%$ based on 4-iodophenylboronic acid and $\sim 25 \%$ based on the amino acid).
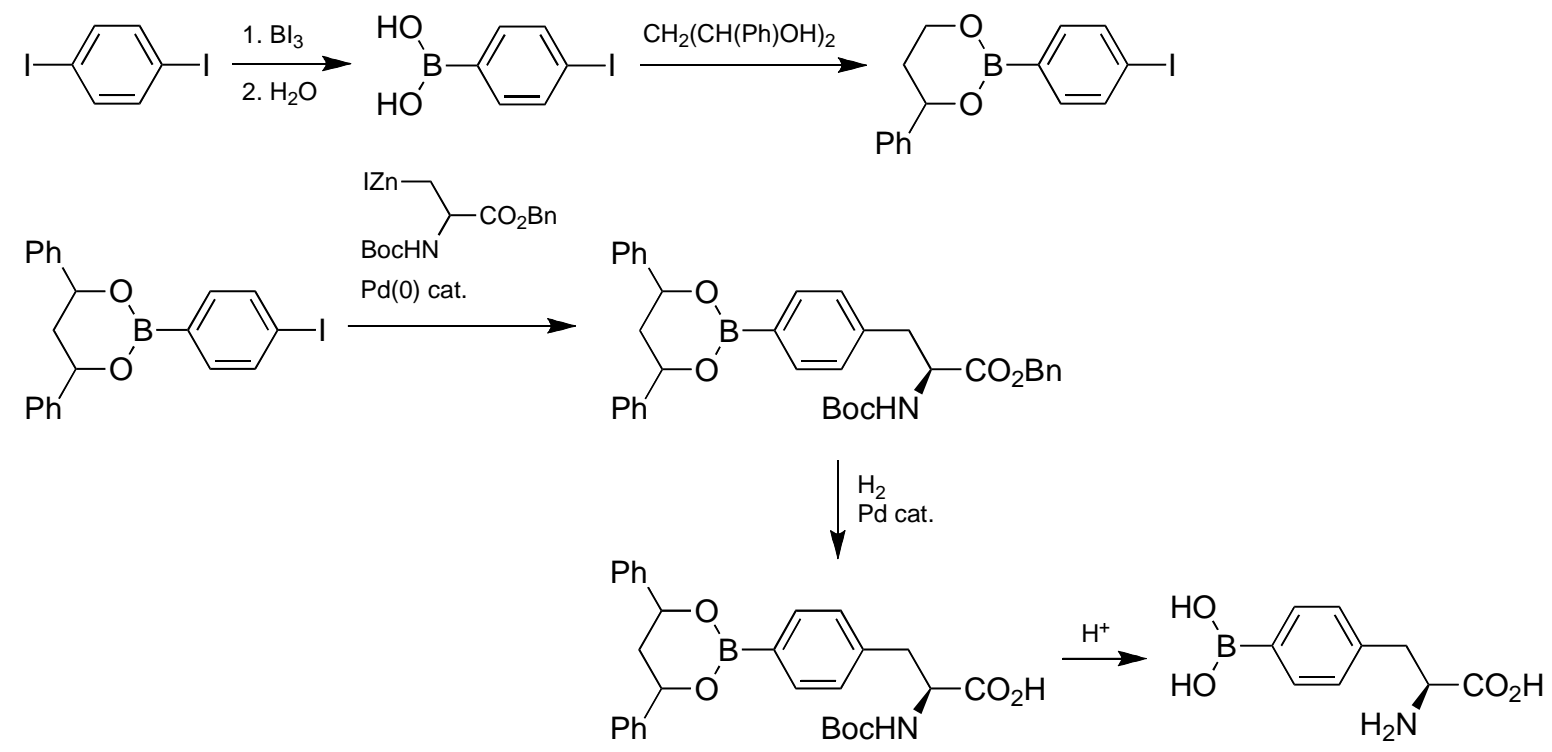

\section{Scheme 8}

\subsection{Introduction of boronic acid group into phenylalanine}

The third group of methods of BPA synthesis is based on the introduction of the dihydroxyboryl substituent directly to the phenylalanine fragment with formation of the $\mathrm{C}-\mathrm{B}$ bond. This approach allows using commercially available enantiomeric amino acids and minimizes transformations of the ${ }^{10} \mathrm{~B}$-enriched product.

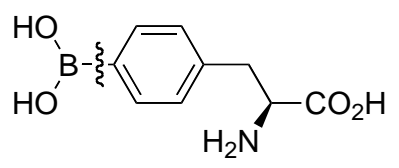


The first synthesis applying this approach was proposed by Malan and Morin in $1998 .{ }^{13}$ It includes the Pd-catalyzed cross-coupling of protected L-4-iodophenyl alanine with diboronic acid dipinacolate followed by removal of protecting groups and results in L-BPA in 53\% yield (based on the amino acid) (Scheme 9).

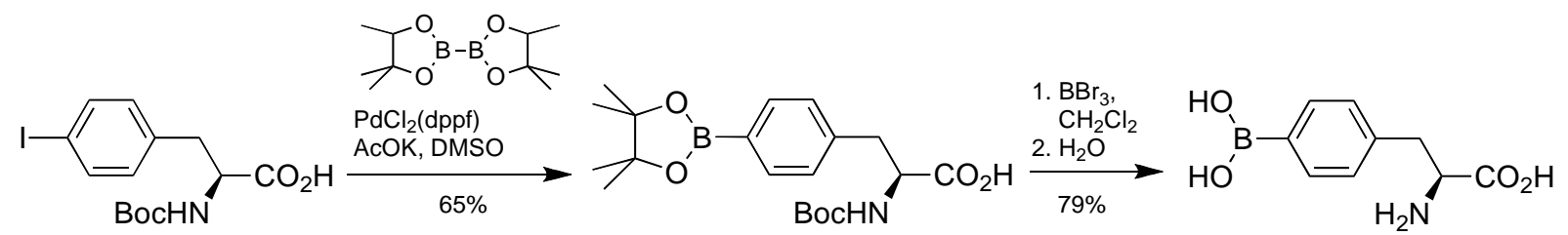

\section{Scheme 9}

The yield of the cross-coupling stage can be boosted up to $88 \%$ by protecting the carboxylic acid of the phenylalanine reactant as benzyl ester. ${ }^{13}$ Another modification of this synthesis protects the carboxylic acid as methyl ester (Scheme 10). ${ }^{14,15}$

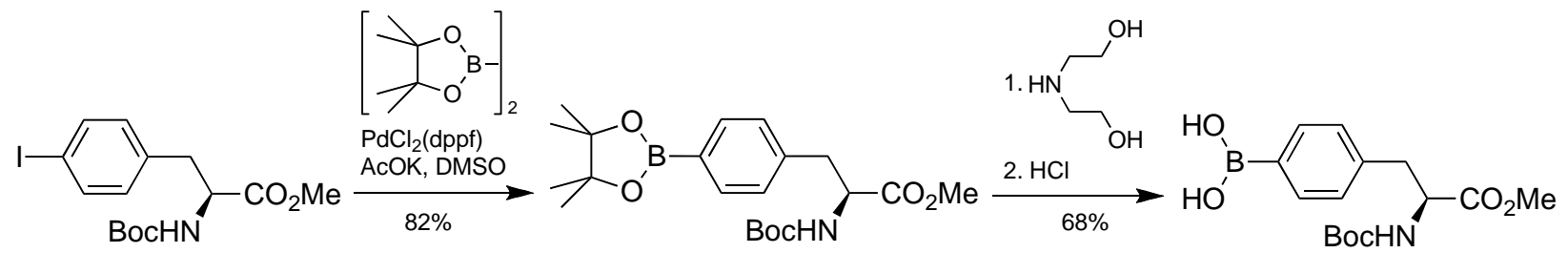

\section{Scheme 10}

Further development of this approach utilizes the more readily available L-tyrosine triflate (instead of L-4-iodophenylalanine) and 1,3-diphenyl-1,3-propanediol ester of diboronic acid (instead of diboronic acid dipinacolate). In the last case the yield of the target product is $48 \%$ (based on the amino acid) (Scheme 11).

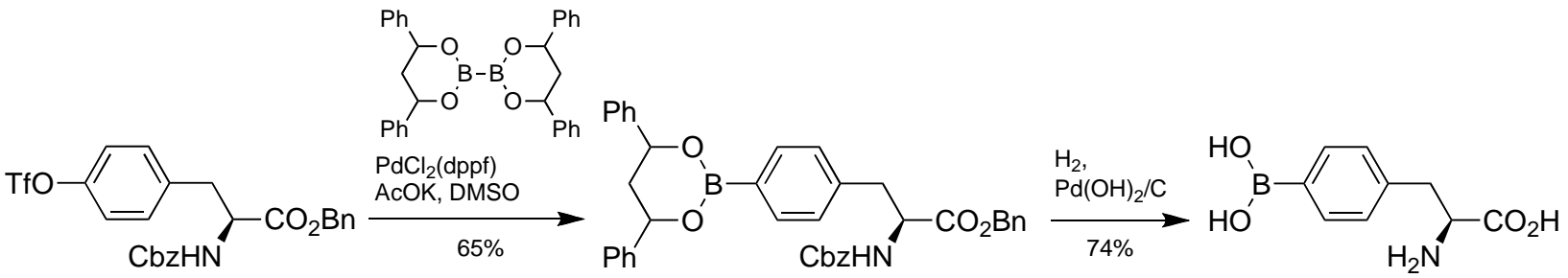

\section{Scheme 11}

The main disadvantages of these good-looking synthetic schemes are low-yields for the multi-step syntheses of the boronating agents ${ }^{13,16}$ and loss of more than $50 \%$ of ${ }^{10} \mathrm{~B}$-enriched materials at the coupling stage. 
A breakthrough took place when the boronating agents were changed for pinacolborane, ${ }^{17}$ which can be easily prepared by the reaction of commercially available borane-dimethylsulfide complex with pinacol. ${ }^{18}$ Surprisingly, in this case the 4-iodo-L-phenylalanine derivatives have been found to be more effective than L-tyrosine triflates and nonaflates (Table 1). ${ }^{19}$

Table 1. Palladium-catalyzed cross-coupling of pinacolborane with 4-iodo-L-phenylalanine and L-tyrosine derivatives

\begin{tabular}{|c|c|c|c|}
\hline \multirow{2}{*}{ Amino acid derivative } & \multirow{2}{*}{$\begin{array}{c}\text { Yield }^{\mathrm{a}} \\
\% \\
\end{array}$} & \multicolumn{2}{|c|}{ Total chemical yield $(\%)$ of L-BPA } \\
\hline & & based on pinacolborane & based on amino acid \\
\hline $\mathrm{CbzHN}$ & $>5$ & - & - \\
\hline DOBn & $58^{\mathrm{b}}$ & 21 & 18 \\
\hline OBn & 82 & 29 & 16 \\
\hline $\mathrm{BBn}$ & 84 & 20 & 19 \\
\hline & 72 & 29 & 35 \\
\hline & 71 & 32 & 21 \\
\hline
\end{tabular}

${ }^{\mathrm{a}}$ Conditions: $3 \mathrm{~mol} \%$ [PdCl2(dppf)], triethylamine, 1,4-dioxane, $80-100{ }^{\circ} \mathrm{C}, 16-36 \mathrm{~h}$.

${ }^{\mathrm{b}}\left[\mathrm{PdCl}_{2}\left(\mathrm{PPh}_{3}\right)_{2}\right]$ used as a catalyst.

Overall the best yield of L-BPA was obtained starting from 4-iodo-L-phenylalanine protected with 3-(benzyloxycarbonyl)oxazolin-5-one (Scheme 12). ${ }^{19}$ 


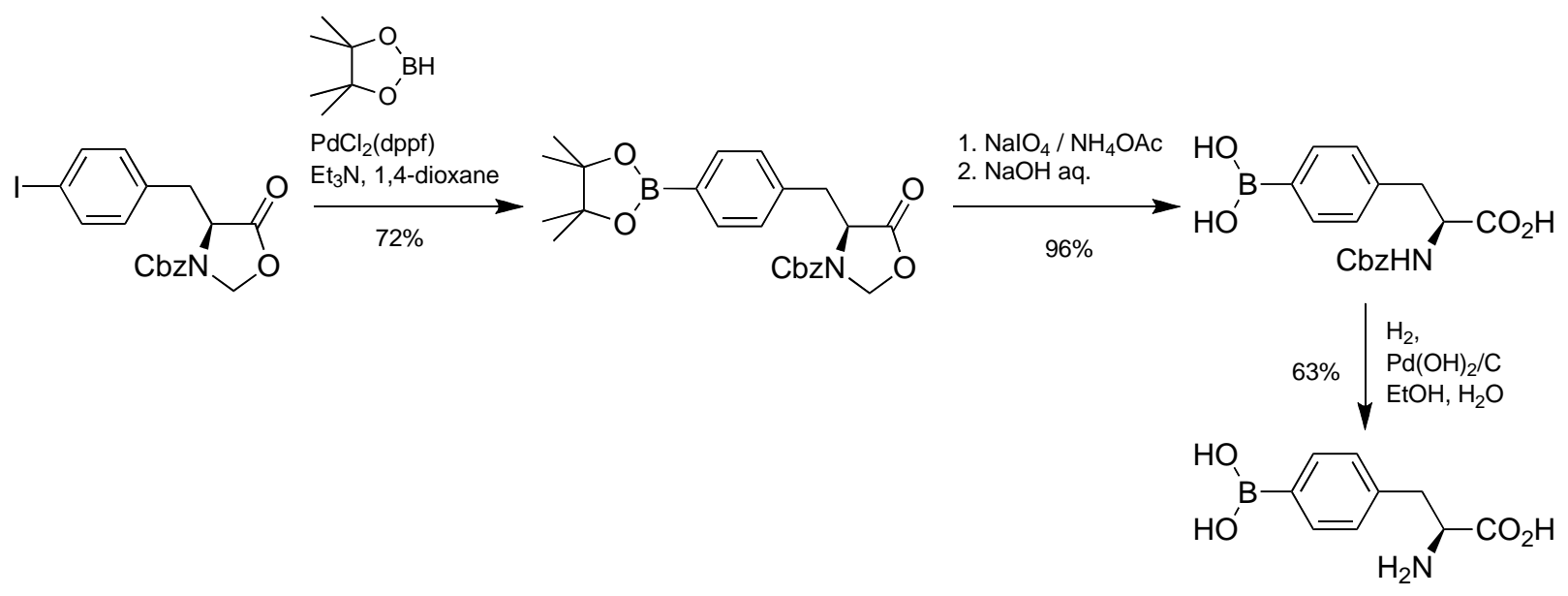

\section{Scheme 12}

The most recent improvement of this method employs ionic liquids $[\mathrm{bmim}][\mathrm{X}],(\mathrm{bmim}=$ 1-butyl-3-methylimidazolium, $\mathrm{X}=\mathrm{BF}_{4}, \mathrm{PF}_{6}$ ) at the cross-coupling stage. The reaction was completed in 20 min producing the boronated phenylalanine in high yield (Scheme 13). The product is readily isolated by simple separation of phases. ${ }^{20}$

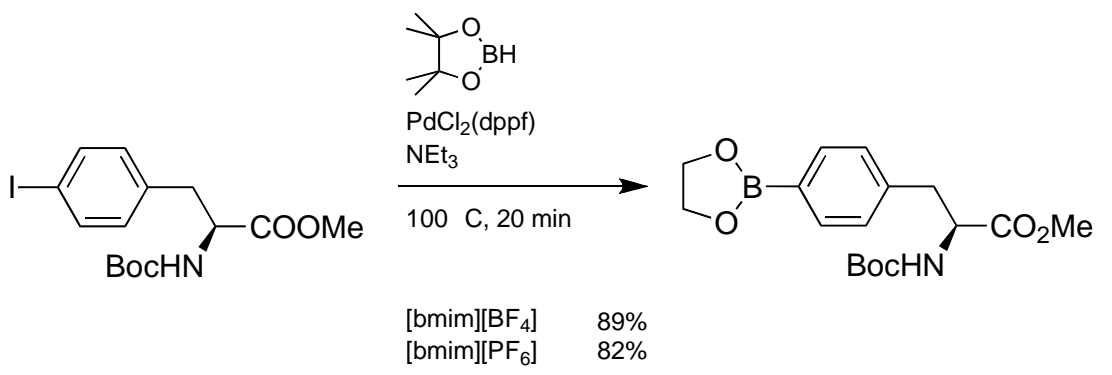

\section{Scheme 13}

In general, contemporary methods of organic synthesis allow synthesizing L-BPA with high efficiency. Some further improvement of the synthetic methods could be achieved by proper choice of the protective groups and deprotection reactions.

\section{Drug Formulation and Delivery}

Drug formulation and delivery is a very important factor, especially if a drug has poor solubility; this is the case for L-BPA having very limited water solubility $(1.6 \mathrm{~g} / \mathrm{L})$. The crystal structure of L-BPA, established by X-ray diffraction method, shows an extended pattern of hydrogen bonding involving the boronic acid, carboxylate and ammonium groups. ${ }^{21}$ 
The first attempt to solve the water solubility problem made use of the hydrochloride salt L-BPA $\cdot \mathrm{HCl}^{22}$ However, the acidity of a $0.1 \mathrm{M}$ solution has been reported with a $\mathrm{pH} \approx 1.5$.

A recent approach is based on tight and reversible esterification of the boronic acid moiety with 1,2- and 1,3-diols (Scheme 14). ${ }^{23-25}$ The interaction between a boronic acid and a diol is known to be one of the strongest single-pair reversible functional group interactions in an aqueous environment and it is widely used for construction of boronic acid-based sugar sensors. $^{24,26-31}$
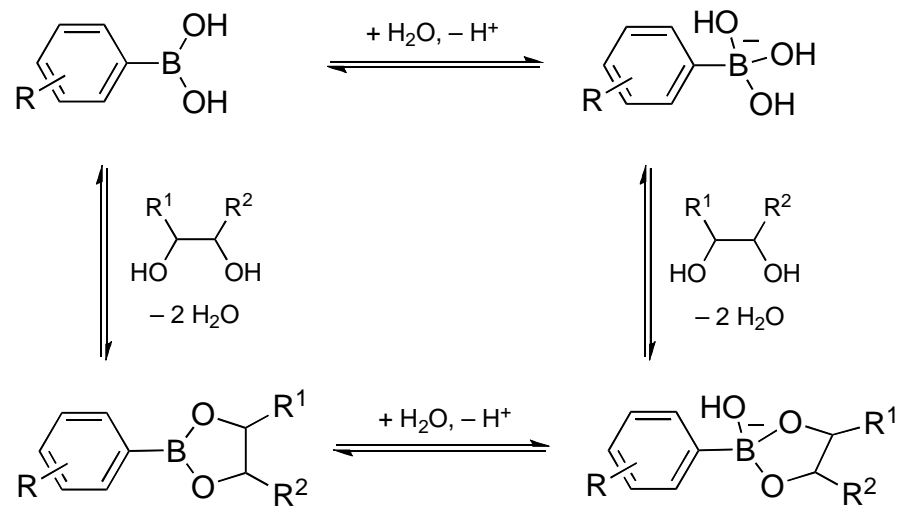

\section{Scheme 14}

Therefore, it is not surprisingly that the formation of esters of L-BPA with monosaccharides (fructose, in particular) was proposed to produce a water soluble form of LBPA for BNCT. ${ }^{32-36}$ Intravenous injection of the L-BPA-fructose complex is now the standard method for its clinical use. According to multinuclear NMR spectroscopy data the L-BPAfructose complex in water buffered at physiological $\mathrm{pH}$ has been found to adopt the structure of $\beta$-D-fructofuranose 2,3,6-(p-phenylalanylorthoboronate). ${ }^{37}$

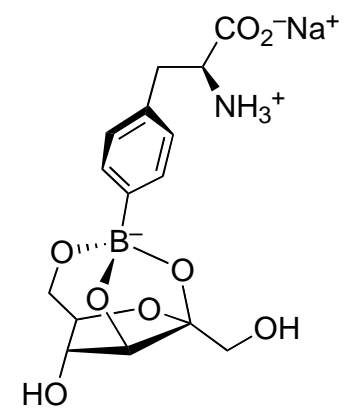

Another approach proposed to obtain water-soluble forms of BPA is the transformation into amides containing water-solubilizing hydroxyl groups. These forms have a high water solubility and lower cytotoxicity than BPA itself and might be suitable boron carriers on BNCT for malignant brain tumor. ${ }^{38-40}$ 

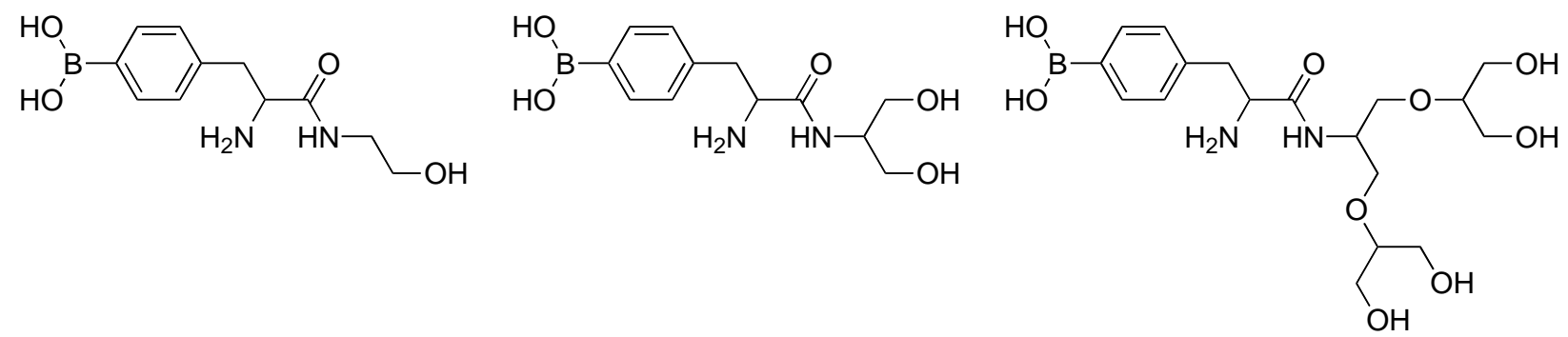

\section{Study of Biodistribution and Pharmacokinetics}

Studying the biodistribution of pharmacokinetics of boron compounds (particularly BPA) is of great importance both for biomedical studies and for planning of patient treatment. Several methods have been developed to determine the boron content of biological research samples taken at biopsy and in tissues obtained from animal biodistribution experiments. These samples are often available in macroscopic quantities of 50-100 $\mathrm{mg}$ or more. Following the oxidative dissolution of weighed tissue samples, boron analysis of the aqueous sample is accomplished with inductively coupled plasma- or direct current plasma-atomic emission spectroscopy (ICPAES and DCP-AES, respectively). These methods determine boron in tissue reliably at a level of 1 ppm. ${ }^{41}$ However, none of these methods can be applied non-invasively for monitoring the in situ boron distribution in patients.

For in vivo imaging of boron compounds, radio-labeled derivatives are of particular interest because their biodistribution can be easily monitored. In many cases, radio-labeling provides detailed information about boron pharmacokinetics that can be used to generate improved patient treatment protocols, for example, by providing information about the required dosage of tumorseeking boron conjugates, and optimal treatment time. Positron emission tomography (PET) using ${ }^{18} \mathrm{~F}$-labeled L-BPA (Scheme 15 ) ${ }^{42}$ has been developed for this purpose and at present is widely used for patient treatment. ${ }^{43-48}$

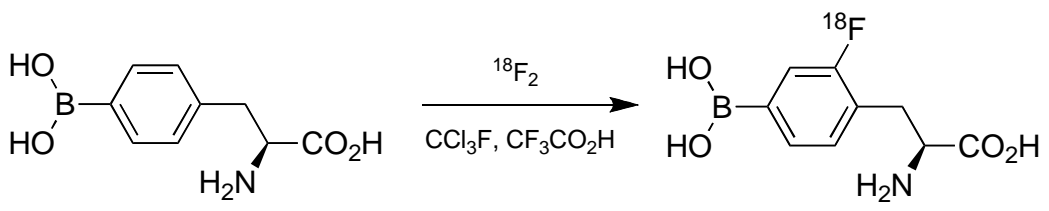

\section{Scheme 15}

Another approach includes PET imaging using ${ }^{11} \mathrm{C}$-labelled L-BPA prepared by a modified Bucherer-Strecker procedure (Scheme 16) followed by separation of the enantiomers by chiral HPLC. ${ }^{49}$ 


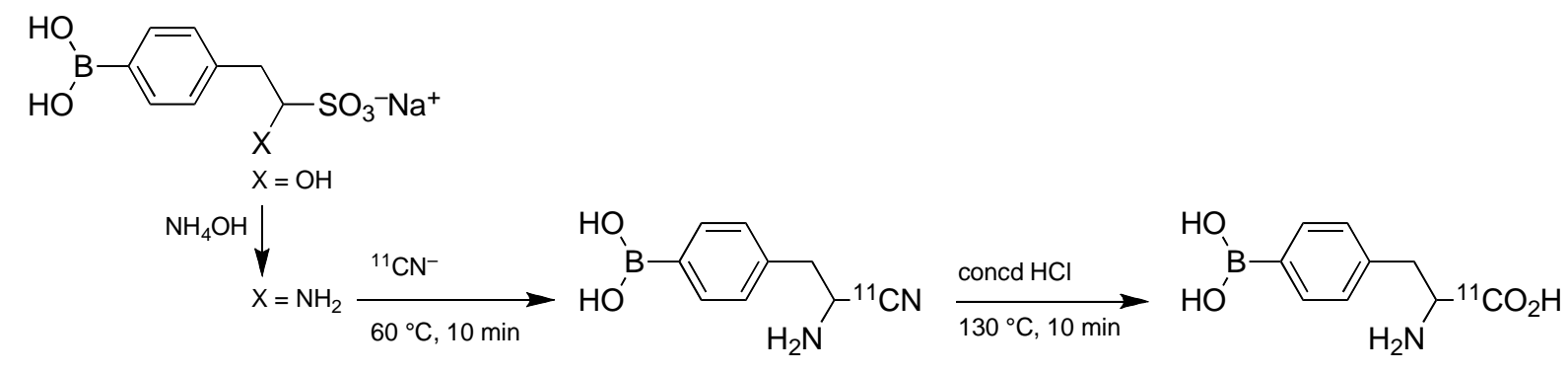

\section{Scheme 16}

${ }^{10} \mathrm{~B}$ and ${ }^{11} \mathrm{~B}$ magnetic resonance imaging (MRI) was proposed as a non-invasive method for the in vivo assessment of BNCT agents, but its practical utilization still remains to be proven. ${ }^{50,51}$ The other recently developed approach is ${ }^{19} \mathrm{~F}$ MRI of fluorine-containing BPA derivatives. ${ }^{52,53}$
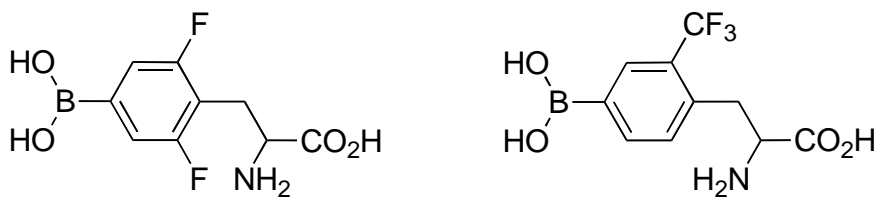

\section{Non-medical Applications - BPA in Organic Synthesis}

Development of effective methods of BPA synthesis resulted in active use of this amino acid and its derivatives in organic synthesis utilizing Pd-catalyzed cross-coupling (Suzuki-Miyaura reaction). This approach was applied to the synthesis of 4-vinyl ${ }^{5}, 4$-aryl $1^{5,15,54,55}$ and 4-heteroaryl (thiophene, ${ }^{5,15,54,55}$ pyridine, ${ }^{5,15,55}$ pyrimidine, ${ }^{5,55}$ pyrazine, ${ }^{55}$ pyridazinone, ${ }^{56}$ quinoline, ${ }^{5}$ benzimidazole $^{55}$ ) derivatives of phenylalanine. Very recently this methodology was used for the introduction of the L-phenylalanine moiety into purine bases, nucleosides and nucleotides. ${ }^{57,58}$ Other examples are the Pd-catalyzed synthesis of L-phenylalanine-based amidine ${ }^{59}$ and the $\mathrm{Cu}-$ mediated reaction with phenols. ${ }^{14}$ Some examples are shown below.
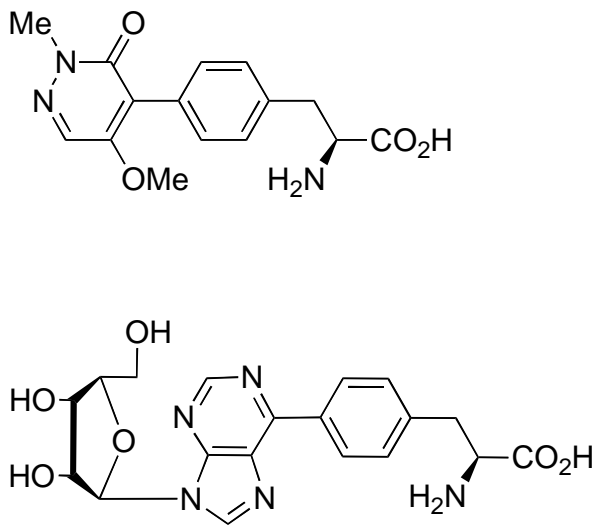<smiles>NC(Cc1ccc(Oc2cc(CC(N)C(=O)O)ccc2O)cc1)C(=O)O</smiles><smiles>CC(=O)C(N)Cc1ccc(C(=N)N)cc1</smiles><smiles>CC(O)[C@H](O)n1c(-c2ccc(CC(N)C(=O)O)cc2)nc(CN)c1N</smiles> 


\section{Conclusions}

Contemporary methods of organic synthesis open ways to the synthesis of L-BPA with high efficiency. Some further improvement of the developed synthetic methods could be achieved by proper choice of the protective groups and deprotection reactions. At present, good availability of L-BPA allows its use in organic synthesis for the preparation of various substituted phenylalanines.

Presently, BPA is the most studied boron-containing amino acid; however, it should be remembered that progress of BNCT caused the synthesis of a wide arsenal of boronated amino acids $;^{60}$ probably, some of these compounds or their analogues could soon find an application as BNCT drugs.

\section{Acknowledgements}

This work was financially supported by the Russian Foundation for Basic Research (grant 08-0300463).

\section{References}

1. Hawthorne, M. F. Angew. Chem., Int. Ed. 1993, 32, 950.

2. Soloway, A. H.; Tjarks, W.; Barnum, B. A.; Rong, F.-G.; Barth, R. F.; Codogni, I. M.; Wilson, J. G. Chem. Rev. 1998, 98, 1515.

3. Snyder, H. R.; Reedy, A. J.; Lennarz, W. J. J. Am. Chem. Soc. 1958, 80, 835.

4. Rajn, N.; Ramalingam, K.; Nowotnik, D. P. Tetrahedron 1992, 48, 10233.

5. Satoh, Y.; Gude, C.; Chan, K.; Firooznia, F. Tetrahedron Lett. 1997, 38, 7645.

6. Roberts, D. C.; Suda, K.; Samanen, J.; Kemp, D. S. Tetrahedron Lett. 1980, 21, 3435.

7. Nakao, H.; Morimoto, T.; Kirihata, M. Biosci. Biotech. Biochem. 1996, 60, 683.

8. Yamamoto, Y.; Seko, T.; Rong, F. G.; Nemoto, H. Tetrahedron Lett. 1989, 30, 7191.

9. Kirihara, M.; Morimoto, T.; Ichimoto, I. Biosci. Biotech. Biochem. 1993, 57, 1940. (b) Kirihara, M.; Morimoto, T.; Ichimoto, I.; Takagaki, M. In: Cancer Neutron Capture Therapy, Mishima, Y. Ed., Plenum Press: New York, 1996; p 99.

10. Park, K. C.; Yoshino, K.; Tomiyasu, H. Synthesis 1999, 2041.

11. Samsel, E. G.; Simpson, B. M. In Progress in Neutron Capture Therapy for Cancer, Allen, B. J.; Moore, D. E.; Harrington, B. V. Eds., Plenum Press: New York, 1992; p 247. (b) Samsel, E. D. U.S. Pat. 5157 149, 1992.

12. Malan, C.; Morin, C. Synlett 1996, 167.

13. Malan, C.; Morin, C. J. Org. Chem. 1998, 63, 8019.

14. Jung, M. E.; Lazarova, T. I. J. Org. Chem. 1999, 64, 2976. 
15. Firooznia,F.; Gude, C.; Chan, K.; Marcopulos, N.; Satoh, Y. Tetrahedron Lett. 1999, 40, 213.

16. Nakamura, H.; Fujiwara, M.; Yamamoto, Y. J. Org. Chem. 1998, 63, 7529. (b) Nakamura, H.; Fujiwara, M.; Yamamoto, Y. In Frontiers in Neutron Capture Therapy, Hawthorne, M. F. Ed., Springer, 2001, p 765. (c) Yamamoto, Y.; Nakamura, H.; Fujiwara, M. U.S. Pat. 6 $031127,2000$.

17. Murata, M.; Watanabe, S.; Masuda, Y. J. Org. Chem. 1997, 62, 6458.

18. Tucker, C. E.; Davidson, J.; Knochel, P. J. Org. Chem. 1992, 57, 3482.

19. Nakamura, H.; Fujiwara, M.; Yamamoto, Y. Bull. Chem. Soc. Jpn. 2000, 73, 231.

20. Zaidlewicz, M.; Sokol, W.; Wolan, A.; Cytarska, J.; Tafelska-Kaczmarek, A.; Dzielendziak, A.; Prewysz-Kwinto, A. Pure Appl. Chem. 2003, 75, 1349. (b) Zaidlewicz, M.; Sokol, W.; Cytarska, J.; Tafelska-Kaczmarek, A.; Wolan, A.; Dzielendziak, A.; Prewysz-Kwinto, A. In Boron Chemistry at the Beginning of the $21^{\text {st }}$ Century, Bubnov, Yu. N. Ed., Editorial URSS: Moscow, 2003, p 78.

21. Shull, B. K.; Spielvogel, D. E.; Gopalaswamy, R.; Sankar, S.; Boyle, P. D.; Head, G.; Devito, K. J. Chem. Soc., Perkin Trans. 2 2000, 557.

22. Ichihashi, M.; Nakanishi, T.; Mishima, Y. J. Invest. Dermatol. 1982, 78, 215.

23. Lorand, J. P.; Edwards, J. O. J. Org. Chem. 1959, 24, 769.

24. Springsteen, G.; Wang, B. Tetrahedron 2002, 58, 5291.

25. Bosch, L. I.; Fyles, T. M.; James, T. D. Tetrahedron 2004, 60, 11175.

26. Wang, J. F.; Jin, S.; Wang, B. H. Tetrahedron Lett. 2005, 46, 7003.

27. Badugu, R.; Lakowicza, J. R.; Geddes, C. D. Bioorg. Med. Chem. 2005, 13, 113.

28. Zhang, Y.; Gao, X.; Hardcastle, K.; Wang, B. Chem. Eur. J. 2006, 12, 1377.

29. Cordes, D. B.; Suri, J. T.; Cappuccio, F. E.; Camara, J. N.; Gamsey, S.; Sharrett, Z.; Thoniyot, P.; Wessling, R. A.; Singaram, B. In: Topics in Fluorescence Spectroscopy. V.11. Glucose Sensing, Geddes, C. D.; Lakowicz, J. R. Eds., Springer: US, 2006; p 47.

30. Kaur, G.; Lin, N.; Fang, H.; Wang, B. In Topics in Fluorescence Spectroscopy. V.11. Glucose Sensing, Geddes, C. D.; Lakowicz, J. R. Eds., Springer: US, 2006; p 377.

31. Akay, S.; Yang, W.; Wang, J.; Lin, L.; Wang, B. Chem. Biol. Drug Design 2007, 70, 279.

32. Mori, Y.; Suzuki, A.; Yoshino, K.; Kakihana, H. Pigment Cell Res. 1989, 2, 273.

33. Yoshino, K.; Suzuki, A.; Mori, Y.; Kakihana, H.; Honda, C.; Mishima, Y.; Kobayashi, T.; Kanda, K. Strahlenther. Onkol. 1989, 165, 127.

34. LaHann, T. R. U.S. Pat. 5492 900, 1996.

35. LaHann, T. R. U.S. Pat. 5935 944, 1999.

36. Shull, B.; Spielvogel, D.; Head, G. U.S. Patent 6169 076, 2001.

37. Shull, B. K.; Spielvogel, D. E.; Head, G.; Gopalaswamy, R.; Sankar, S.; Devito, K. J. Pharm. Sci. 2000, 89, 215.

38. Nemoto, H.; Iwamoto, S.; Nakamura, H.; Yamamoto, Y. Chem. Lett. 1993, 22, 465.

39. Nemoto, H.; Cai, J.; Asao, N.; Iwamoto, S.; Yamamoto, Y. J. Med. Chem. 1995, 38, 1673.

40. Takagaki, M.; Ono, K.; Oda, Y.; Kikuchi, H.; Nemoto, H.; Iwamoto, S.; Cai, J.; Yamamoto, Y. Cancer Res. 1996, 56, 2017. 
41. Probst, T. U. Fresenius J. Anal. Chem. 1999, 364, 391.

42. Eskola, O.; Vähätalo, J.; Lehikoinen, P.; Bergman, J.; Forsback, S.; Solin, O. J. Labelled Compd. Radiopharm. 2001, 44, S849. (b) Vähätalo, J. K.; Eskola, O.; Bergman, J.; Forsback, S.; Lehikoinen, P.; Jääskeläinen, J.; Solin, O. J. Labelled Compd. Radiopharm. 2002, 45, 697.

43. Nichols, T. L.; Kabalka, G. W.; Miller, L. F.; Khan, M. K.; Smith, G. T. Med. Phys. 2002, 29, 2351.

44. Takahashi, Y.; Imahori, Y.; Mineura, K. Clin. Cancer Res. 2003, 9, 5888.

45. Kabalka, G. W.; Nichols, T. L.; Smith, G. T.; Miller, L. F.; Khan, M. K.; Busse, P. M. J. Neuro-Oncol. 2003, 62, 187.

46. Wang, H. E.; Liao, A. H.; Deng, W. P.; Chang, P. F.; Chen, J. C.; Chen, F. D.; Liu, R. S.; Lee, J. S.; Hwang, J. J. J. Nucl. Med. 2004, 45, 302.

47. Chen, J. C.; Chang, S. M.; Hsu, F. Y.; Wang, H. E.; Liu, R. S. Appl. Radiat. Isot. 2004, 61, 887.

48. Wang, H. E.; Wu, S. Y.; Chang, C. W.; Liu, R. S.; Hwang, L. C.; Lee, T. W.; Chen, J. C.; Hwang, J. J. Nucl. Med. Biol. 2005, 32, 367.

49. Studenov, A.; Ding, Y.-S.; Ferrieri, R.; Miura, M.; Coderre, J.; Fowler, J. S. J. Labelled Compd. Radiopharm. 2001, 44, S345.

50. Bendel, P.; Zilberstein, J.; Salomon, Y. Magn. Reson. Med. 1994, 32, 170.

51. Bendel, P. NMR Biomed. 2005, 18, 74.

52. Hattori, Y.; Asano, T.; Niki, Y.; Kondoh, H.; Kirihata, M.; Yamaguchi, Y.; Wakamiya, T. Bioorg. Med. Chem. 2006, 14, 3258.

53. Hattori, Y.; Yamamoto, Y.; Ando, H.; Kondoh, H.; Asano, T.; Kirihata, M.; Yamaguchi, Y.; Wakamiya, T. Bioorg. Med. Chem. 2007, 15, 2198.

54. Firoonzia, F.; Gude, C.; Chan, K.; Satoh, Y. Tetrahedron Lett. 1998, 39, 3985.

55. Gong, Y.; He, W. Org. Lett. 2002, 4, 3803.

56. Gong, Y.; Barbay, J. K.; Dyatkin, A. B.; Miskowski, T. A.; Kimball, E. S.; Prouty, S. M.; Fisher, M. C.; Santulli, R. J.; Schneider, C. R.; Wallace, N. H.; Ballentine, S. A.; Hageman, W. E.; Masucci, J. A.; Maryanoff, B. E.; Damiano, B. P.; Andrade-Gordon, P.; Hlasta, D. J.; Hornby, P. J.; He, W. J. Med. Chem. 2006, 49, 3402.

57. Čapek, P.; Hocek, M. Synlett 2005, 3005.

58. Čapek, P.; Pohl, R.; Hocek, M. Org. Biomol. Chem. 2006, 4, 2278.

59. Kusturin, C. L.; Liebeskind, L. S.; Neumann, W. L. Org. Lett. 2002, 4, 983.

60. Kabalka, G. W.; Yao, M.-L. Anti-Cancer Agents Med. Chem. 2006, 6, 111. 